\title{
The Essential and Enigmatic Role of ABC Transporters in Bt Resistance of Noctuids and Other Insect Pests of Agriculture
}

\author{
David G. Heckel
}

Citation: Heckel, D.G. The Essential and Enigmatic Role of ABC Transporters in Bt Resistance of Noctuids and Other Insect Pests of Agriculture. Insects 2021, 12, 389. https://doi.org/10.3390/ insects12050389

Academic Editors: Gaelle Le Goff and Ralf Nauen

Received: 5 April 2021

Accepted: 26 April 2021

Published: 28 April 2021

Publisher's Note: MDPI stays neutral with regard to jurisdictional claims in published maps and institutional affiliations.

Max Planck Institute for Chemical Ecology, Hans-Knoell-Str. 8, D-07745 Jena, Germany; heckel@ice.mpg.de; Tel.: +49-3641-57-1599

Simple Summary: The insect family, Noctuidae, contains some of the most damaging pests of agriculture, including bollworms, budworms, and armyworms. Transgenic cotton and maize expressing Cry-type insecticidal proteins from Bacillus thuringiensis (Bt) are protected from such pests and greatly reduce the need for chemical insecticides. However, evolution of Bt resistance in the insects threatens the sustainability of this environmentally beneficial pest control strategy. Understanding the interaction between $\mathrm{Bt}$ toxins and their targets in the insect midgut is necessary to evaluate the risk of resistance evolution. ABC transporters, which in eukaryotes typically expel small molecules from cells, have recently been proposed as a target for the pore-forming Cry toxins. Here we review the literature surrounding this hypothesis in noctuids and other insects. Appreciation of the critical role of $\mathrm{ABC}$ transporters will be useful in discovering counterstrategies to resistance, which is already evolving in some field populations of noctuids and other insects.

Abstract: In the last ten years, $\mathrm{ABC}$ transporters have emerged as unexpected yet significant contributors to pest resistance to insecticidal pore-forming proteins from Bacillus thuringiensis (Bt). Evidence includes the presence of mutations in resistant insects, heterologous expression to probe interactions with the three-domain Cry toxins, and CRISPR/Cas9 knockouts. Yet the mechanisms by which ABC transporters facilitate pore formation remain obscure. The three major classes of Cry toxins used in agriculture have been found to target the three major classes of $A B C$ transporters, which requires a mechanistic explanation. Many other families of bacterial pore-forming toxins exhibit conformational changes in their mode of action, which are not yet described for the Cry toxins. Three-dimensional structures of the relevant $\mathrm{ABC}$ transporters, the multimeric pore in the membrane, and other proteins that assist in the process are required to test the hypothesis that the ATP-switch mechanism provides a motive force that drives Cry toxins into the membrane. Knowledge of the mechanism of pore insertion will be required to combat the resistance that is now evolving in field populations of insects, including noctuids.

Keywords: Bacillus thuringiensis; Cry protein; ATP-Binding Cassette; ABC Transporter; ATP switch model; pore-forming toxin; resistance; genetics; Noctuidae; Helicoverpa; Spodoptera; Heliothis; Chloridea; Trichoplusia

\section{Introduction}

$\mathrm{ABC}$ proteins are a huge and ancient superfamily of proteins that are defined by the presence of a domain called the ATP-binding cassette [1]. Binding to ATP causes this domain to change its shape, and this conformational change has been harnessed for many purposes. The ABCE1 protein is required for termination of protein translation, where its lever-like action separates the large and small ribosomal subunits [2]. The Rad50 protein is invoked when chromosomes are damaged, by clamping onto DNA like tweezers to bring the strands together for repair [3]. The ABC transporters possess membrane-spanning helices that change orientation to squeeze small molecules across membranes when the ABC domain binds to ATP [4]. The most recently discovered property of ABC proteins 
is their role in the mode of action of pore-forming three-domain Cry toxins from Bacillus thuringiensis $(\mathrm{Bt})$, the subject of this review.

The Cry toxins are important in agriculture because cotton, maize, and other crops have been transformed with genes from $\mathrm{Bt}$ to enable the plants to manufacture enough toxins to kill certain pest caterpillars that feed on them. See [5] for a comprehensive list of Bt toxins. When ingested along with plant tissue, the toxins form pores in the larval midgut epithelium, lysing the cells and eventually killing the insect. In 2019, 108.7 million hectares of transgenic Bt crops were grown worldwide [6], greatly reducing the use of chemical insecticides. The sustainability of this strategy is threatened by the evolution of resistance, which is already appearing in field populations of some pest insects (see [7] for a useful overview). Studies of Bt-resistant insects provided the first evidence for $\mathrm{ABC}$ transporters in the Cry toxin mode of action.

Cry1-type toxins are particularly potent against polyphagous noctuid pests, primarily the heliothines and the armyworms. The cotton bollworm Helicoverpa armigera (Hübner) was formerly distributed in Asia, Africa, and Australia, but has recently invaded South America. Its resistance to chemical insecticides and its ability to hybridize with the native corn earworm Helicoverpa zea (Boddie) has promoted its spread. H. zea populations in North America are evolving resistance to Cry1 Ab-expressing maize. Chloridea (formerly Heliothis) virescens (Fabricius), the tobacco budworm [8], is a pest of cotton and other crops that has been well-controlled by Bt-cotton up to now. We will use the genus name Heliothis in this review for continuity with the literature cited. The fall armyworm Spodoptera frugiperda (J. E. Smith) has recently invaded Africa, India, Asia, and Australia from its home in the New World to become a worldwide pest of maize. Its congeners, the beet armyworm Spodoptera exigua (Hübner) and cotton leafworm Spodoptera litura (Fabricius), are also polyphagous pests. The cabbage looper Trichoplusia ni (Hübner) has evolved resistance to Dipel in greenhouses. Cry1 toxins are also effective against non-noctuid Lepidoptera, such as the diamondback moth Plutella xylostella (L), a worldwide pest of crucifer crops and the first insect to evolve Bt resistance in open field populations, and the domesticated silkworm Bombyx mori (L), a model insect for which powerful genetic tools have been developed. Cry1 resistance has appeared in some populations of the European corn borer Ostrinia nubilalis (Hübner) and the Asian corn borer Ostrinia furnacalis (Guenée). Cry2 toxins are active against many of the same Lepidoptera. The pink bollworm Pectinophora gossypiella has evolved resistance to Cry2-expressing Bt-transgenic cotton. The Cry3 toxins are potent against Coleoptera, such as Diabrotica virgifera (LeConte), the corn rootworm. $A B C$ transporters of these non-noctuids will also be discussed as they illustrate the common features of the mode of action of the three-domain Cry toxins. Cell lines from noctuids have also been important in Bt research, including Sl-HP from S. litura, Sf9 from S. frugiperda, Hi5 from T. $n i$, and QB-Ha-E5 from H. armigera.

Unfortunately, there is no standard nomenclature yet for insect $A B C$ transporters, which is becoming a problem for comparative studies as more and more are implicated as Bt targets. Gene and protein names provided by automatic annotation at NCBI do not uniquely identify them or reveal their relationship to the $A B C$ transporters described here. The most reliable point of reference is the genome of $B$. mori, the first to be sequenced among Lepidoptera. Figure 1 shows the genomic context of the B. mori orthologs of the proteins discussed in this review. Figure 2 shows their predicted membrane topology. 


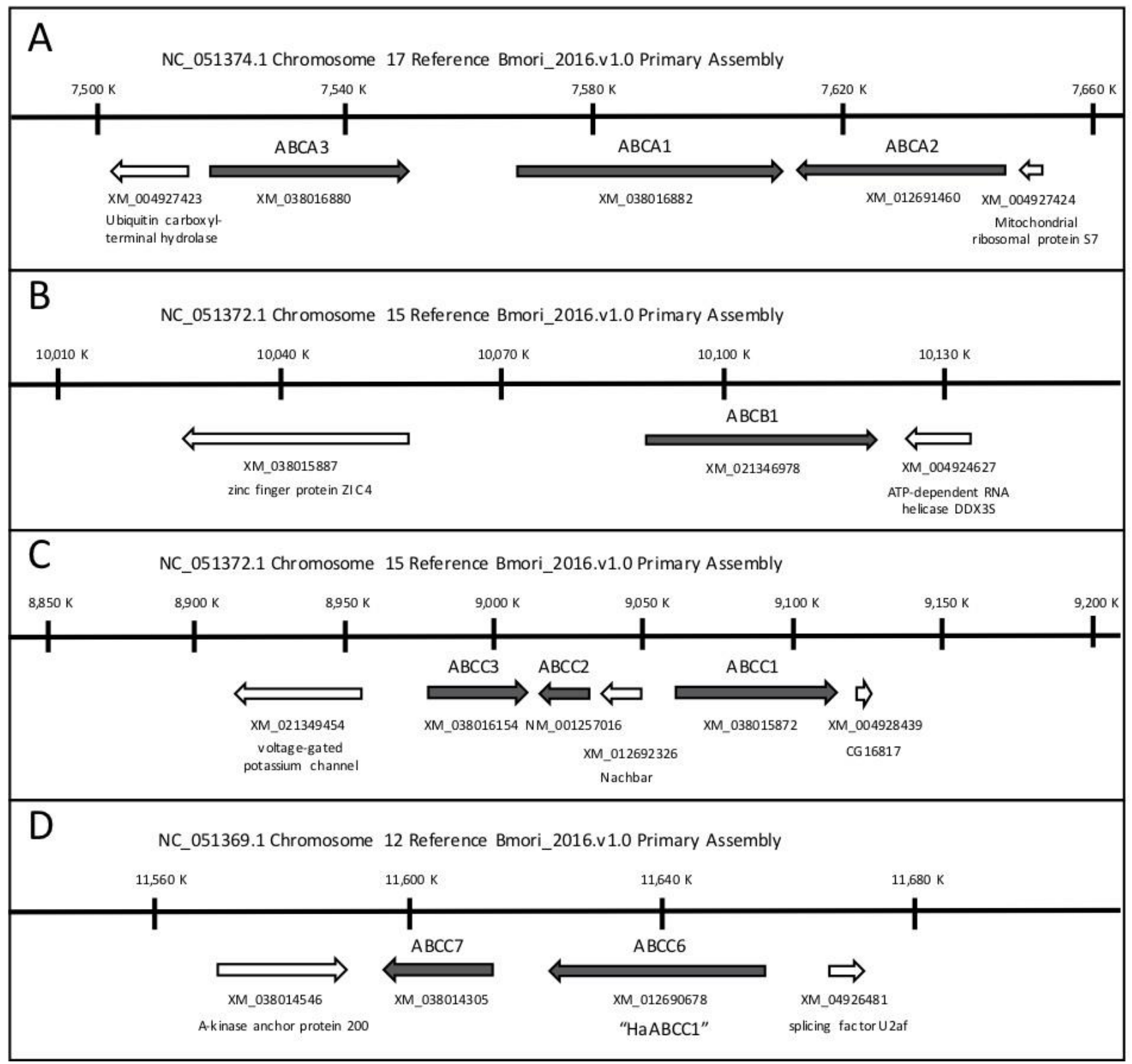

Figure 1. Genomic location of Bombyx mori (A-C) transporters orthologous to those interacting with three-domain Cry proteins described in the text. Coordinates are based on the chromosome view on NCBI (https:/ / www.ncbi.nlm.nih.gov/, accessed on 2 April 2021) and are the same as shown in the new version of Kaikobase [9]. (D) Names for ABCC6 and ABCC7 are defined here for the first time, to avoid confusion with the previously named ABCC1. 

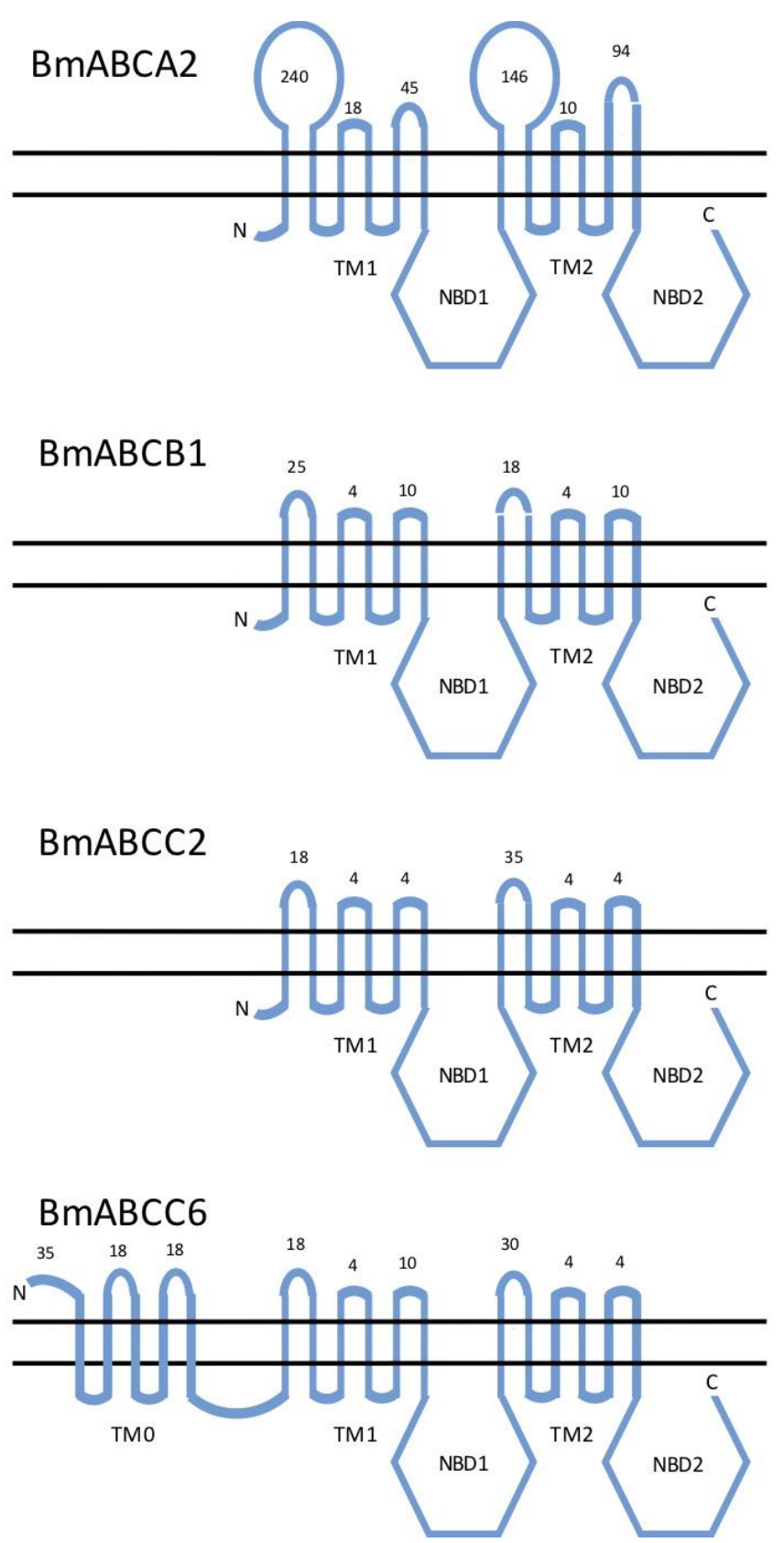

Figure 2. Phobius $[10,11]$ predictions of membrane topology in the lipid bilayer of four ABC transporters from Bombyx mori orthologous to those interacting with three-domain Cry proteins described in the text (not to scale). The external lumenal surface is on top. Numbers of residues in each predicted external loop are shown. Transmembrane domains: TM0, TM1, and TM2. Nucleotide-binding domains: NBD1, NBD2. The N-terminus and C-terminus of each polypeptide is indicated.

\section{Initial Discoveries}

$\mathrm{ABC}$ transporters were first discovered as targets of $\mathrm{Bt}$ toxins by positional cloning in strains of resistant insects. Despite decades of research on Bt resistance, there was no previous biochemical or physiological evidence that ABC transporters could be involved. The discovery of their role was a surprise, and only the independent efforts by three groups that converged on the same protein has convinced the research community that understanding their role in resistance is important, as described in several recent reviews [5,12-23]. Solving this problem holds the key to developing strategies to combat the increasing problem of Bt resistance. 
A mutation in the ABCC2 protein was identified in a Cry1Ac-resistant strain of $H$. virescens, by positional cloning using markers from the early versions of the $B$. mori genome sequence, well before a genome sequence for $H$. virescens was available [24]. Evidence that this mutation was important for resistance came from mapping, binding studies, and an allele frequency change correlated with the increase of resistance over time [24]. Like most ABC mutations subsequently found in other species, and like the cadherin mutation previously found in H. virescens [25] it introduced a frameshift and prevented expression of the full-length protein in the membrane. This contrasts with many cases of chemical insecticide resistance, where deletion of the target would be lethal.

Even stronger evidence came from analysis of a more subtle mutation in the ABCC2 protein in B. mori [26]. Positional cloning using the genome sequence converged on ABCC2, but no incapacitating mutation could be found. Instead, the protein in the Cry1Ab-resistant strain had several amino acid substitutions and an insertion of a tyrosine in an extracellular loop. Germline transformation was used to prove that one copy of the susceptible allele inserted in the resistant genetic background could confer Cry1Ab-susceptibility on the resistant strain [26], and subsequent experiments [27] proved that the inserted tyrosine was necessary and sufficient for resistance.

A similar approach using bulked segregant analysis based on cDNA markers identified $\mathrm{ABCC} 2$ and its neighboring gene ABCC 3 as contributing to Cry1Ac and Cry1Ca resistance in S. exigua [28]. In contrast to the previous mutations, ABCC2 carried a lesion in an intracellular nucleotide-binding domain (NBD). Suppression of ABCC2 and ABCC3 by RNA inhibition (RNAi) increased the tolerance of susceptible larvae to Cry1Ac and Cry1Ca. This independent and unbiased positional cloning approach extended the phenomenon to a third genus, and to a third type of mutation in ABCC2, proving that $A B C$ transporters could no longer be ignored in the mode of action of Cry toxins.

\section{Search for ABC Mutants in Resistant Strains from Field and Laboratory}

These early findings motivated the search for the involvement of ABC transporters in other Bt-resistant strains of noctuids and other Lepidoptera. Comparative linkage mapping with markers, previously shown to be linked to ABCC2 in H. virescens, was used to identify a mutation that eliminated the last transmembrane domain of ABCC2 in Cry1Acresistant P. xylostella from Hawaii [29]. The same study localized Cry1Ac resistance in T. ni from British Columbia to a region containing ABCC2, although a specific mutation was not identified [29]; a different resistance mechanism, altered aminopeptidase expression, was also identified in the same strain of T. ni [30]. Mis-spliced transcripts of ABCC2 generating a truncated protein were found in a Cry1Ac-resistant strain of $H$. armigera from China [31]. Another comparative linkage mapping approach identified a genomic region containing $\mathrm{ABCC} 2$ in a laboratory-selected Cry1F-resistant strain of $O$. nubilalis from collections in the Corn Belt of the USA [32], although involvement of ABCC2 has not yet been confirmed in field-evolved Cry1F resistance in O. nubilalis from Nova Scotia [33]. In Puerto Rico, rapid appearance of Cry1F resistance in $S$. frugiperda stimulated withdrawal of the transgenic maize variety from the market, and was found to be associated with mutations in ABCC2 [34]. Additional mutations in S. frugiperda ABCC2 were associated with Cry1Fa and Cry1A.105 resistance in Puerto Rico [35] and Brazil [36]. Screening for some of these was included in surveys using DNA diagnostics for resistance to chemical insecticides as well as $\mathrm{Bt}[37,38]$.

The only member of the ABCB family to be investigated in Lepidoptera as a target of Cry toxins initially came to attention because it was down-regulated in a Cry1Ac-resistant strain of P. xylostella. PxABCB1 expression was found to be lower in other resistant strains, was further reduced by additional Cry1Ac selection, and was suppressed by RNAi in susceptible strains, which increased their tolerance to Cry1Ac [39]. 


\section{Functional Studies}

Heterologous expression of $\mathrm{ABC}$ transporters in insect cell lines has been extensively used to probe their function. The crucial role of the tyrosine insertion in loop 2 of $B$. mori $\mathrm{ABCC} 2$ in conferring Cry1 $\mathrm{Ab}$ resistance was convincingly shown by expression in Sf9 cells [27]. The same study demonstrated the synergy of the cadherin BtR175 and ABCC2 for the first time; co-expression of both made the cells much more susceptible to Cry $1 \mathrm{Ab}$ than either one alone. These results were recapitulated using proteins from $\mathrm{H}$. virescens in Sf9 cells [40], with the added information that synergy was observed only when both proteins were expressed in the same cell; i.e., not from a mixture of cells expressing one or the other, as might be expected from the sequential binding hypothesis [41]. The mechanism of synergy was further probed by comparing the ability of the cadherin from $H$. armigera or S. litura to synergize Cry1Ac action on H. armigera ABCC2 expressed in Hi5 cells [42]. Although the S. litura cadherin was an ineffective synergist, when cadherin repeat 11 from $H$. armigera was swapped in, synergistic activity increased. The authors hypothesized that specific binding sites on the cadherin localized the toxin to a good position for interaction with $\mathrm{ABCC} 2$ in a species-specific manner [42]. A similar species-specific synergism with ABCC2 from S. exigua and the cadherin from S. exigua (but not H. armigera) was observed with the Cry1C toxin in Sf9 cells [43]. Domain-swapping between Cry1C and Cry1Ac was used to infer that domains II and III of Cry1Ac have different binding sites on ABCC2 of S. exigua [44]. ABCC2 from S. frugiperda expressed in Hi5 cells conferred sensitivity to Cry $1 \mathrm{Ab}$ and $\mathrm{Cry} 1 \mathrm{Fa}$, while the cadherin did not, but synergism was not investigated in this study [45]. ABCC3 from S. frugiperda was also found to confer sensitivity to Cry $1 \mathrm{Ab}$ and Cry1Fa under similar conditions [46].

A wide-ranging study explored the specificity of the toxin-target interaction by expressing $\mathrm{ABC}$ transporters from Lepidoptera, Coleoptera, Diptera, and humans in Sf9 cells and testing them with lepidopteran- or coleopteran-active toxins [47]. ABCC2 or ABCC3 from B. mori conferred sensitivity to Cry1Aa, but not Cry1Ca or Cry1Da. The latter two must have different, unknown targets because they are active on caterpillars of some lepidopteran species. Human and dipteran ABC transporters tested did not respond to lepidopteran- or coleopteran-active toxins.

D. melanogaster is not normally susceptible to Cry1Ac, but when ABCC2 was expressed in the midgut of transgenic larvae, Cry1Ac in the artificial diet killed them [48]. Moreover, the genome of $D$. melanogaster lacks the ortholog of the 12-cadherin domain protein found in all Lepidoptera, so the killing mechanism did not rely on the same type of synergism from the cadherin. However, synergism could be observed when the transgenic larvae were fed peptide fragments from lepidopteran cadherins along with Cry1Ac [48].

The most sensitive measurements of the interaction between Cry toxins and their receptors have been made using heterologous expression in Xenopus oocytes [49]. Messenger RNA experimentally injected into these huge cells is translated and the proteins (e.g., ABCC2 or cadherin) are incorporated into the egg membrane. This technique is often used to investigate the properties of ion channels using the voltage-clamp technique. The current through the channel is measured as a function of the experimentally-fixed voltage gradient across the membrane and the resulting graph characterizes the electrophysiological properties of the channel. In this case, the channel is the Cry toxin pore inserted into the membrane, which allows inward cation flux. The dynamics of current flow depend on the details of pore insertion and structure. Using this sensitive technique, it was shown that expression of the cadherin alone produced almost no current, expression of ABCC2 allowed abundant current, and expression of both produced even more current- the most convincing demonstration of synergism to date.

The mechanism of synergism is still obscure, but a number of hypotheses can be envisaged, which are not mutually exclusive (Figure 3). These can be classified into transacting mechanisms where synergism can occur when the cadherin and $\mathrm{ABC}$ transporter may be separated from each other, and cis-acting mechanisms where synergism requires a close physical interaction. According to the sequential binding hypothesis [41], toxin 
monomers bind to the cadherin and are further processed by cleavage of the $\mathrm{N}$-terminal $\alpha 1$-helix, whereupon they form oligomeric pre-pores in solution (Figure 3A). However, toxin monomer binding to the cadherin is not an absolute requirement for toxicity; cadherin knockouts can still be killed by higher toxin amounts [24,50-52] and Cry1Ac is still lethal to $T$. $n i$ dispite not being able to bind to the T. ni cadherin [53]. Synergism is due to presence of the cadherin, which speeds up a process that happens at a slower rate in its absence. Here the pre-pore structure can diffuse away from the cadherin to interact with a remote $\mathrm{ABC}$ transporter, so this mechanism is classified as trans-acting. If, however the cadherin traps the toxin and brings it to the $\mathrm{ABC}$ transporter, this would be a cisacting mechanism (Figure $3 \mathrm{~B}$ ). This could be synergistic if there are many more cadherin molecules in the membrane than $\mathrm{ABCC} 2$ molecules. Another previously suggested cisacting mechanism [40] is shown in Figure 3C, where the cadherin pulls the pre-pore away from the $A B C$ transporter, enabling it to insert into the membrane and freeing up the $A B C$ transporter for the next pre-pore.

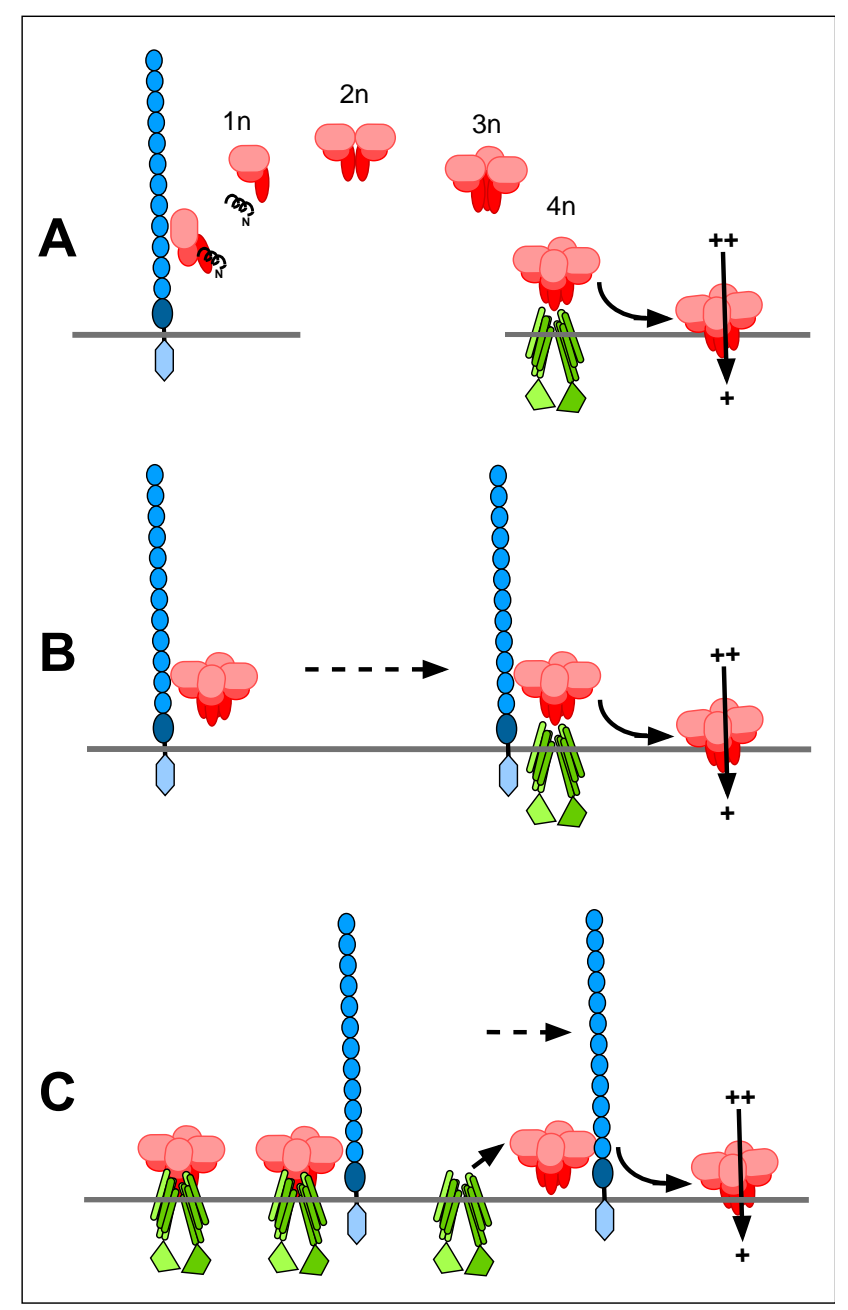

Figure 3. Hypothetical models of the mechanism of synergy between the 12-cadherin domain protein and an ABC transporter. (A) Trans-acting synergy, due to acceleration of oligomer formation following monomer binding to the cadherin. (B) Cis-acting synergy, due to the cadherin trapping the pre-pore and moving it to the $\mathrm{ABC}$ transporter. (C) Cis-acting synergy, due to the cadherin pulling the pre-pore away from the $\mathrm{ABC}$ transporter, freeing it to interact with another toxin pre-pore. Dotted lines represent movement of the cadherin within the membrane. 


\section{Extracellular Loops}

Most of the ABC protein is out of reach of $\mathrm{Bt}$ toxins approaching the cell, since the nucleotide binding domains are entirely cytoplasmic, and most of the transmembrane domains are buried within the lipid bilayer (Figure 2). Extracellular loops connecting adjacent transmembrane helices are very short in $\mathrm{ABCC}$ proteins, but larger in $\mathrm{ABCB}$ and especially $A B C A$ proteins. Detailed analyses of the interaction between extracellular loops of $B$. mori $\mathrm{ABC}$ transporters and various domains of Cry1A toxins have been carried out by the group of Ryoichi Sato in Tokyo. Following the discovery that insertion of a single tyrosine in Loop 2 of $\mathrm{ABCC} 2$ conferred resistance to $\mathrm{Cry} 1 \mathrm{Ab}$ in larvae, swapping other amino acids for the inserted tyrosine blocked pore formation in cells expressing the transporter, while amino acid substitutions at other positions in the non-inserted loop did not [54]. Thus, the size of the loop, rather than its amino acid composition, was the more important determinant of sensitivity. Domain-swapping within the toxin implicated Domain II as most important in this interaction. Subsequent mutagenesis of Domain II of Cry1Aa revealed a region that bound both to $\mathrm{ABCC} 2$ and another important receptor, the cadherin BtR175 [55]. While ABCC3 had much lower binding affinities to Cry1Aa and $\mathrm{Cry} 1 \mathrm{Ab}$ than $\mathrm{ABCC} 2$, binding was increased in constructs containing partial loops from ABCC2 [56]. Another group pointed out an amino acid difference within Loop 1 of ABCC2 of $S$. frugiperda and S. litura that correlated with binding affinity to Cry1Ac, and they also replicated the binding difference by creating two versions of the H. armigera $\mathrm{ABCC} 2$, one with each amino acid [57].

\section{Regulatory Changes}

Regulatory changes involving $\mathrm{ABC}$ transporters were also found to confer resistance. In a Cry1Ac-resistant strain of $P$. xylostella, resistance mapped to the vicinity of ABCC 2 but no disruptive mutations in the gene could be found [58]. Instead, the expression level of $\mathrm{ABCC} 2$ and $\mathrm{ABCC} 3$ was found to be controlled by the mitogen-activated protein kinase (MAPK) signaling pathway, with the MAP4K4 gene located close by on the same genomic scaffold, accounting for the mapping results. Constitutive expression of MAP4K4 in the resistant strain suppressed $\mathrm{ABCC} 2, \mathrm{ABCC} 3$, and alkaline phosphatase, another Cry1 Acbinding protein. RNA interference (RNAi) suppression of MAP4K4 transiently restored susceptibility by upregulating $\mathrm{ABCC} 2$ and $\mathrm{ABCC} 3$. Thus, resistance in this case was due to higher expression of a negative regulator of $\mathrm{ABCC} 2$ transcription.

The Forkhead Box Protein A (FOXA) transcription factor was found to stimulate transcription of $\mathrm{ABCC} 2$ and $\mathrm{ABCC} 3$ in $\mathrm{H}$. armigera, as predicted from FOXA binding sites in the promoters [59]. RNAi silencing of FOXA downregulated $A B C C 2$ and $A B C C 3$ and increased the tolerance of susceptible larvae to Cry1Ac. Parallel results were obtained by expression in Sl-HP cells in the same study. A different study screened several members of the GATA transcription factor family from $H$. armigera and found that GATAe caused Sf9, QB-Ha-E5, and Hi5 cell lines to increase their expression of ABCC2, conferring greater Cry1Ac sensitivity [60]. If either mechanism were to be found in resistant strains from the field, resistance would be due to lower expression of a positive regulator of ABCC2 transcription.

Comparison of the ABCC2 coding sequence across many species of Lepidoptera identified a conserved region targeted by the microRNA miR-998-3p [61]. MicroRNAs bind to messenger RNAs in a sequence-specific fashion and target them for destruction or inhibit translation. Injection of an agomir (a chemically modified RNA that mimics the effect of the miRNA) into susceptible larvae of P. xylostella, S. exigua, or H. armigera increased their tolerance of Cry1Ac and decreased the abundance of ABCC2 mRNA. Injection of an antagomir (a single-stranded molecule designed to block the effect of the miRNA) into larvae of Cry1Ac-resistant $P$. xylostella reduced their tolerance of Cry1Ac and increased their ABCC2 mRNA levels. 


\section{Cell Lines}

The influential colloid-osmotic lysis theory to explain how Cry toxins kill cells was developed using different cell lines that naturally differed in their susceptibilities to two different toxins [62]. It would be interesting to determine which $A B C$ transporters are naturally expressed by those cells. Sl-HP cells from S. litura are susceptible to activated Cry1Ac even though S. litura larvae are not. ABCC 3 was found to be expressed in this cell line, and RNA inhibition of ABCC3 decreased Sl-HP sensitivity to Cry1Ac [63]. In another study, comparison of Cry1Ac sensitivities of cell lines from different tissues produced the order midgut $>$ fat body $>$ ovary as expected, but unexpectedly fat body-derived cells were most susceptible to Cry2Ab toxin [64]. Surveys of heterologous expression of candidate targets in cell lines [65] should also take their native expression patterns into account.

\section{Cry2A Toxins}

An extensive sampling effort in Australia employing the F2 screen [66] yielded strains of $\mathrm{H}$. armigera and H. punctigera with high levels of resistance to the Cry2Ab toxin. Linkage mapping with these strains revealed several different mutations in the ABCA2 gene that prevented expression of the full-length protein [67]. Unlike the ABCC proteins, ABCA2 has two very large ectodomains (Figure 2), and because the mutants are extremely resistant to $\mathrm{Cry} 2 \mathrm{Ab}$, it was speculated that the single $\mathrm{ABCA} 2$ protein functions similarly to the sequential binding model for the cadherin and ABCC2 [67]. Linkage mapping in a strain of $T$. $n i$ that was selected with Dipel in British Columbia greenhouses [68] eventually resulted in the identification of a transposable element in ABCA2 conferring Cry2Ab resistance [69]. Mis-splicing mutants in ABCA2 were associated with Cry2Ab resistance in P. gossypiella in a laboratory-selected strain from Arizona and field populations from India [70]. Additional crosses confirmed these mutations but suggested that an additional, uncharacterized mechanism was also involved in Cry2Ab resistance in this species [71].

A different member of the ABCC family from H. armigera (GenBank Accession No. KY796050) was also found to bind Cry2Ab, identified by the authors as "HaABCC1" [72], although it is not the ortholog of the ABCC1 (BGIBMGA007737+38) on B. mori Chromosome 15 next to $\mathrm{ABCC} 2$ and $\mathrm{ABCC} 3$ described previously $[24,26,28]$. The ortholog of "HaABCC1" in B. mori is part of a small cluster on Chromosome 12 (Figure 1D) of ABCC proteins with 5 additional $\mathrm{N}$-terminal transmembrane domains as well as two very large ectodomains, unlike the Chromosome $15 \mathrm{ABCC} 1-\mathrm{ABCC} 2-\mathrm{ABCC} 3$ cluster in B. mori and other Lepidoptera (Figure 2). Although the authors speculated on the role of $A B C C$ proteins in cross-resistance between Cry1 Ac and Cry2Ab, no binding or toxicity studies were performed with Cry1 Ac, and the strain of $\mathrm{H}$. armigera used was susceptible to both Cry1 Ac and Cry2Ab [72]. The use of a name already assigned to another gene has unfortunately created the false impression that the results are relevant to cross-resistance. Here we designate this gene as ABCC6 (Figures 1D and 2).

\section{CRISPR/Cas9 Knockouts}

CRISPR/Cas9 knockouts provide a very useful tool to investigate gene function in non-model organisms. The first use of the technique to knock out $\mathrm{ABC}$ transporters in Lepidoptera targeted the half-transporter genes white, scarlet, and ok in Helicoverpa armigera [73]. These are homologs of the well-known pigment transporters white, scarlet, and brown in Drosophila melanogaster, and as expected, the knockouts affected adult eye color and larval skin pigmentation. Homozygotes for the white knockout, however, were embryonic lethal in H. armigera and in the milkweed bug [74], which was unexpected because these are viable in Drosophila, Aedes, and Tribolium. Lethality has also complicated the interpretation for some knockouts of Cry toxin targets.

Knockouts of $\mathrm{ABCA} 2$ in a susceptible strain of $H$. armigera conferred $>100$-fold resistance to Cry2Aa and Cry2Ab, and eliminated Cry2Ab binding to BBMV, but did not affect resistance or binding to Cry1 Ac [75]. After mapping Cry2Ab resistance in T. ni to ABCA2, where a transib mobile element was found to disrupt the gene, either ABCA1 or ABCA2 
were knocked out in a susceptible strain and only $\mathrm{ABCA} 2$ was found to affect $\mathrm{Cry} 2 \mathrm{Ab}$ tolerance [69]. Knockouts of the ABCA2 gene in B. mori (using the TALEN technique) conferred Cry2A resistance on larvae, and heterologous expression of ABCA2 in HEK239 cells confirmed the absence of cross-resistance to Cry1A, Cry1Ca, Cry1Da, Cry1Fa, and Cry9Aa toxins [76].

In P. xylostella, a knockout of ABCC2 conferred 724-fold resistance to Cry1Ac and a knockout of $\mathrm{ABCC} 3$ conferred 413-fold resistance to the same toxin. Each knockout greatly reduced BBMV binding to Cry1Ac, but the double knockout was not made in this study [77]. Somewhat different results were obtained in another study of the same species [78], in which single knockouts were weakly resistant ( 4-fold) and only the double knockout was $>8000$-fold resistant to Cry1Ac. So far there is no explanation for the differing results in $P$. xylostella. A study in $\mathrm{H}$. armigera, however, produced results closer to the second study, in that single knockouts of $\mathrm{ABCC} 2$ and $\mathrm{ABCC} 3$ were weakly resistant to Cry $1 \mathrm{Ac}$, while the double knockout was $>15,000$-fold resistant [79].

Knocking out $\mathrm{ABCC} 2$ in O. furnacalis conferred $>300$-fold resistance to Cry1Fa but less than 10-fold resistance to Cry1 Ab or Cry1Ac and no resistance to Cry1Aa [80]. Knocking out ABCC2 in S. frugiperda increased tolerance to either Cry1Fa or Cry1Ab $>120$-fold, while knocking out ABCC3 increased tolerance by a lesser amount ( $>16$-fold); in this study the double knockout was reported to be lethal [46]. In S. exigua, an ambitious study created single knockouts of $\mathrm{ABCC} 1, \mathrm{ABCC} 2$, or $\mathrm{ABCC} 3$, as well as the cadherin and an aminopeptidase, and examined susceptibility to Cry1Ac, Cry1Fa, and Cry1Ca. Among the 15 pairwise comparisons, $\mathrm{ABCC} 2$ had a strong effect and the cadherin a weak effect on Cry1Ac or Cry1Fa tolerance, and ABCC2 also had a weak effect on Cry1Ca tolerance [52].

CRISPR/Cas9 knockout experiments are useful in confirming the role of a given ABC transporter in susceptibility to a given toxin, and when more than one knockout and more than one toxin are compared, in assessing their relative importance. The possibility of non-target effects needs more investigation, in order to reconcile studies where double knockouts are lethal with those where they confer even more resistance, since these studies make diametrically opposed recommendations for resistance management. Targeting the nucleotide binding domains would increase the probability of nontarget effects, since these are more highly conserved across $\mathrm{ABC}$ family members. In addition, no knock-ins have been reported yet for $\mathrm{ABC}$ transporters, as in the case of another Bt resistance gene, tetraspanin [81].

\section{Negative Cross-Resistance with Chemical Insecticides}

The intriguing possibility that mutations in $A B C$ transporters could interfere with the insect's ability to use them to rid itself of other toxins has motivated many recent studies. With the increasing use of Bt sprays and transgenic plants in the 1990s, the issue of cross-resistance between $\mathrm{Bt}$ and chemical insecticides had achieved some attention, but Bt resistance mechanisms had not been characterized at the molecular level. More recently, in 2016 when several chemical insecticides were screened against an ABCC2-mutant strain of $H$. armigera, abamectin and spineotram were more toxic compared with their activity against a Cry1Ac-susceptible strain [82]. Measurements of higher abamectin concentrations in mutant larvae and transfected cells were consistent with the bioassay results. RNAi silencing of ABCC2 decreased susceptibility to Cry1Ac and increased susceptibility to abamectin [82]. However, the selective differential exerted by abamectin on the Cry1Acresistant versus Cry1Ac-susceptible strains was small, and not all subsequent studies have confirmed the effect.

Single and double knockouts of $\mathrm{ABCC} 2$ and $\mathrm{ABCC} 3$ in H. armigera produced in a different study were not more susceptible to abamectin or spinetoram [79]. The knockout of ABCC2 in O. furnacalis was not more susceptible to abamectin or chlorantraniliprole [80]. On the other hand, single knockouts of ABCC2 or ABCC3 in S. frugiperda were more susceptible to abamectin and spinosad (while the double knockout was reported to be lethal and could not be compared) [46]. Another study on S. frugiperda found that a 
Cry1F-resistant strain isolated from the field with a frameshift mutation in ABCC2 had lower sensitivity to bifenthrin and higher sensitivity to spinetoram; yet when ABCC2 was knocked out in a different strain, Cry1F resistance increased 25-fold but sensitivity to chlorantraniliprole, bifenthrin, spinetoram, and acephate was unchanged [83]. Knocking out the P-glycoprotein ABCB1 in S. exigua increased, rather than decreased, susceptibility to abamectin and emamectin benzoate [84]; whether this protein is orthologous to the coleopteran ABCB1 (see below) has not been determined. Contradictory results were obtained in a study of ABCC2 in P. xylostella [85]; HEK-293 cells stably transformed with ABCC2 accumulated less avermectin, but down-regulating ABCC2 in vivo with RNAi had no effect on avermectin or chlorfenapyr tolerance.

Although results are suggestive in some studies, the changes in tolerance to the conventional insecticides examined are small and would not be useful in a resistancebreaking approach against ABCC mutations, as mortality of Bt-resistant insects would not be much greater than their Bt-susceptible counterparts. Only a few insecticides have been examined so far, and some with a greater effect are likely to be found eventually in a wider screen.

\section{ABCB (P-glycoprotein) and Cry3 Toxins in Coleoptera}

A different family of $A B C$ transporters, the P-glycoproteins $(\mathrm{ABCB})$, is involved in toxicity of the Cry3 toxins in Coleoptera. Linkage mapping in a strain of the poplar leaf beetle Chrysomela tremula (Fabricius) resistant to transgenic Cry3Aa-expressing poplar identified a frameshift in the ABCB1 protein, and heterologous expression of $\mathrm{ABCB} 1$ in Sf9 cells conferred susceptibility to Cry3Aa in vitro [86]. In the western corn rootworm D. virgifera virgifera, heterologous expression of the orthologous $\mathrm{ABCB} 1$ protein also conferred Cry $3 \mathrm{~A}$ sensitivity on Sf9 and HEK-293 cells in vitro, and an mCry3A-resistant strain was found to have deletions in the $\mathrm{ABCB} 1$ gene [87].

Whether the beetle ABCB1 genes are orthologous to PxABCB1 from P. xylostella mentioned in Section 3 above [39] is not known; Cry3 toxins were not experimentally tested in that study. The authors pointed out structural similarities among Cry1 and Cry3 toxins, and searched for but could not find PxABCB1 in the fragmented Plutella genome sequence. We have found that the Bombyx ortholog maps to Chromosome 15, about $1 \mathrm{MB}$ away from the ABCC cluster (Figure 1B). More studies are required to confirm the involvement of the P-glycoproteins in Cry1A toxin interactions in Lepidoptera, and to establish the generality of the P-glycoproteins as targets of the beetle-active Cry3 toxins. Cross-resistance studies suggest the existence of additional, different targets in beetles [88].

\section{Other $A B C$ Transporters in Lepidoptera}

Suppression of the white gene in P. xylostella by RNAi reduced Cry1Ac susceptibility but was not lethal [89]; as pointed out earlier, CRISPR/Cas9 knockouts of white were lethal in H. armigera [73]. Suppression of $\mathrm{ABCH} 1$ in P. xylostella caused larval mortality but did not affect Cry1Ac resistance [90]. A gene in O. furnacalis identified as ABCG was downregulated in Cry1 $\mathrm{Ab}$ - and Cry1Ac-resistant strains [91]; it is evidently not orthologous to either of the two genes in P. xylostella. No mutations in half-transporter ABCG or ABCH family genes have yet been identified in Bt-resistant Lepidoptera.

\section{Hypotheses on the Mechanism of Pore Insertion}

The lack of three-dimensional structures of the ABCC2 or ABCA2 proteins, the Cry toxin pore embedded in the membrane, and the toxin-binding region of the cadherin has inhibited the development of detailed hypotheses on the manner by which $A B C$ transporters facilitate pore insertion. $\mathrm{ABC}$ transporters could simply be another binding site on the membrane surface, increasing the local toxin concentration and increasing the rate of pore insertion, due to a concentration effect. It has been hypothesized that ABCC2 facilitates the formation of the pre-pore oligomer, in a manner similar to the cadherin [92]. It was hypothesized that active opening and closing of the $\mathrm{ABC}$ transporter channel would 
be required to pull the pre-formed pore into the membrane [13]. This hypothesis would seem to be refuted by results with a mutant $A B C C 2$ from $S$. exigua lacking the second nucleotide-binding domain [93], as well as engineered mutants of ABCC2 from B. mori lacking nucleotide-binding domains [94].

As previously pointed out [15], it is difficult to explain how evolution in Bacillus thuringiensis has resulted in Cry2A-type toxins that target ABCA proteins, Cry1A-type toxins that target $\mathrm{ABCC}$ proteins, and Cry3B-type toxins that target $\mathrm{ABCB}$ proteins, without invoking some fundamental property that unites these very different $A B C$ transporters. If the shared ATP-switch mechanism powering substrate transport [4] is not such a property, then we are left without a mechanistic explanation of the pore-insertion process for the threedomain Cry proteins [13]. Many other bacterial pore-forming toxins enter the membrane with dynamic conformational changes, for example Vip3A [95] or the Membrane Attack Complex [96], or the Tc toxin [97]. Whether such a dynamic process is required for Cry toxin pore formation deserves more investigation. A reasonable hypothesis at this point is that the dynamism comes from the toxin-target interaction, not just the toxin.

\section{Future Perspectives}

Since the first description in 2010, mutations in ABC transporters have emerged as the most important type of mutation causing resistance to the three-domain Cry toxins of Bacillus thuringiensis. Yet mechanistic studies have lagged behind those on other poreforming toxins with much more complicated structures. Why? Not enough effort has been expended on determining the three-dimensional structures that will be required for a full understanding of how the toxin interacts with membrane proteins to form a membrane pore. Since the first two structures of trypsin-activated monomers of the threedomain Cry toxins revealed their structural similarity [98,99], many more have appeared confirming that this similarity is fundamental. Recently a structure of the entire protoxin was determined [100], revealing additional domains that might potentiate pore formation in some way. The low-hanging fruit has been harvested. Lacking is a structure of any ABC transporter known to interact with a Cry toxin. Lacking is a structure of any cadherin known to interact with a Cry toxin. Lacking is a structure of the Cry toxin pore in the membrane. Without these structures, theorizing about how Bt toxins work is fantasy. Recent advances in electron cryo-microscopy (cryo-EM) have made these structures attainable. It is now time to attain them.

Funding: Preparation of this review was funded by the Max-Planck-Gesellschaft. The funder had no role in the design of the study; in the collection, analyses, or interpretation of data; in the writing of the manuscript, or in the decision to publish the results.

Data Availability Statement: NCBI GenBank: www.ncbi.nlm.nih.gov, accessed on 2 April 2021. Kaikobase: kaikobase.dna.affrc.go.jp, accessed on 2 April 2021.

Acknowledgments: I thank Linda J. Gahan for years of fruitful collaboration at Clemson University, and the U. S. National Science Foundation for finally funding our grant proposal for positional cloning in Heliothis virescens on the seventh submission.

Conflicts of Interest: The author declares no conflict of interest.

\section{References}

1. Holland, I.B.; Cole, S.P.C.; Kuchler, K.; Higgins, C.F. (Eds.) ABC Proteins. From Bacteria to Man; Academic Press: London, UK, 2003; $647 \mathrm{p}$.

2. Navarro-Quiles, C.; Mateo-Bonmati, E.; Micol, J.L. ABCE Proteins: From Molecules to Development. Front. Plant Sci. 2018, 9, 1125. [CrossRef]

3. Hopfner, K.P.; Karcher, A.; Shin, D.S.; Craig, L.; Arthur, L.M.; Carney, J.P.; Tainer, J.A. Structural biology of Rad50 ATPase: ATP-driven conformational control in DNA double-strand break repair and the ABC-ATPase superfamily. Cell 2000, 101, 789-800. [CrossRef]

4. Higgins, C.F.; Linton, K.J. The ATP switch model for ABC transporters. Nat. Struct. Mol. Biol. 2004, 11, 918-926. [CrossRef] [PubMed] 
5. Adang, M.J.; Crickmore, N.; Jurat-Fuentes, J.L. Diversity of Bacillus thuringiensis Crystal Toxins and Mechanism of Action. In Insect Midgut and Insecticidal Proteins; Dhadialla, T.S., Gill, S.S., Eds.; Academic Press: London, UK, 2014 ; Volume 47, pp. 39-87.

6. ISAAA. Global Status of Commercialized of Biotech/GM Crops in 2019: Biotech Crops Drive Socio-Economic Development and Sustainable Environment in the New Frontier; International Service for the Acquisition of Agri-Biotech Applications: Ithaca, NY, USA, 2019.

7. Tabashnik, B.E.; Carrière, Y. Successes and Failures of Transgenic Bt Crops: Global Patterns of Field-evolved Resistance. In Bt Resistance-Characterization and Strategies for GM Crops Producing Bacillus Thuringiensis Toxins; Soberón, M., Gao, Y., Bravo, A., Eds.; CABI: Wallingford, UK, 2015; Volume 4, pp. 1-14.

8. Pogue, M.G. Revised status of Chloridea Duncan and (Westwood), 1841, for the Heliothis virescens species group (Lepidoptera: Noctuidae: Heliothinae) based on morphology and three genes. Syst. Entomol. 2013, 38, 523-542. [CrossRef]

9. Yang, C.C.; Yokoi, K.; Yamamoto, K.; Jouraku, A. An update of KAIKObase, the silkworm genome database. Database J. Biol. Databases Curation 2021. [CrossRef]

10. Käll, L.; Krogh, A.; Sonnhammer, E.L.L. A combined transmembrane topology and signal peptide prediction method. J. Mol. Biol. 2004, 338, 1027-1036. [CrossRef] [PubMed]

11. Käll, L.; Krogh, A.; Sonnhammer, E.L.L. Advantages of combined transmembrane topology and signal peptide prediction-The Phobius web server. Nucleic Acids Res. 2007, 35, W429-W432. [CrossRef]

12. Dermauw, W.; Van Leeuwen, T. The ABC gene family in arthropods: Comparative genomics and role in insecticide transport and resistance. Insect Biochem. Mol. Biol. 2014, 45, 89-110. [CrossRef]

13. Heckel, D.G. Learning the ABCs of Bt: ABC transporters and insect resistance to Bacillus thuringiensis provide clues to a crucial step in toxin mode of action. Pestic. Biochem. Physiol. 2012, 104, 103-110. [CrossRef]

14. Heckel, D.G. Roles of ABC Proteins in the Mechanism and Management of Bt Resistance. In Bt Resistance-Characterization and Strategies for GM Crops Producing Bacillus Thuringiensis Toxins; Soberón, M., Gao, Y., Bravo, A., Eds.; CABI: Wallingford, UK, 2015; Volume 4, pp. 98-106.

15. Heckel, D.G. How do toxins from Bacillus thuringiensis kill insects? An evolutionary perspective. Arch. Insect Biochem. Physiol. 2020, 104, 21673. [CrossRef]

16. Jurat-Fuentes, J.L.; Heckel, D.G.; Ferre, J. Mechanisms of Resistance to Insecticidal Proteins from Bacillus thuringiensis. Annu. Rev. Entomol. 2021, 66, 121-140. [CrossRef]

17. Merzendorfer, H. ABC Transporters and Their Role in Protecting Insects from Pesticides and Their Metabolites. Adv. Insect Physiol. 2014, 46, 1-72. [CrossRef]

18. Mitsuhashi, W.; Miyamoto, K. Interaction of Bacillus thuringiensis Cry toxins and the insect midgut with a focus on the silkworm (Bombyx mori) midgut. Biocontrol. Sci. Technol. 2020, 30, 68-84. [CrossRef]

19. Pardo-López, L.; Soberón, M.; Bravo, A. Bacillus thuringiensis insecticidal three-domain Cry toxins: Mode of action, insect resistance and consequences for crop protection. FEMS Microbiol. Rev. 2013, 37, 3-22. [CrossRef] [PubMed]

20. Sato, R.; Adegawa, S.; Li, X.Y.; Tanaka, S.; Endo, H. Function and Role of ATP-Binding Cassette Transporters as Receptors for 3D-Cry Toxins. Toxins 2019, 11, 124. [CrossRef] [PubMed]

21. Tabashnik, B.E. ABCs of Insect Resistance to Bt. PLoS Genet. 2015, 11, e1005646. [CrossRef] [PubMed]

22. Wu, C.; Chakrabarty, S.; Jin, M.H.; Liu, K.Y.; Xiao, Y.T. Insect ATP-Binding Cassette (ABC) Transporters: Roles in Xenobiotic Detoxification and Bt Insecticidal Activity. Int. J. Mol. Sci. 2019, 20, 2829. [CrossRef] [PubMed]

23. Heckel, D.G. A return to the pore-Dissecting Bacillus thuringiensis toxin mode of action via voltage clamp experiments. FEBS J. 2016, 283, 4458-4461. [CrossRef] [PubMed]

24. Gahan, L.J.; Pauchet, Y.; Vogel, H.; Heckel, D.G. An ABC Transporter Mutation Is Correlated with Insect Resistance to Bacillus thuringiensis Cry1Ac Toxin. PLoS Genet. 2010, 6, 1001248. [CrossRef]

25. Gahan, L.J.; Gould, F.; Heckel, D.G. Identification of a gene associated with Bt resistance in Heliothis virescens. Science 2001, 293, 857-860. [CrossRef]

26. Atsumi, S.; Miyamoto, K.; Yamamoto, K.; Narukawa, J.; Kawai, S.; Sezutsu, H.; Kobayashi, I.; Uchino, K.; Tamura, T.; Mita, K.; et al. Single amino acid mutation in an ATP-binding cassette transporter gene causes resistance to Bt toxin Cry1Ab in the silkworm, Bombyx mori. Proc. Natl. Acad. Sci. USA 2012, 109, E1591-E1598. [CrossRef]

27. Tanaka, S.; Miyamoto, K.; Noda, H.; Jurat-Fuentes, J.L.; Yoshizawa, Y.; Endo, H.; Sato, R. The ATP-binding cassette transporter subfamily C member 2 in Bombyx mori larvae is a functional receptor for Cry toxins from Bacillus thuringiensis. FEBS J. 2013, 280, 1782-1794. [CrossRef]

28. Park, Y.; González-Martínez, R.M.; Navarro-Cerrillo, G.; Chakroun, M.; Kim, Y.; Ziarsolo, P.; Blanca, J.; Canizares, J.; Ferré, J.; Herrero, S. ABCC transporters mediate insect resistance to multiple Bt toxins revealed by bulk segregant analysis. BMC Biol. 2014, 12, 46. [CrossRef]

29. Baxter, S.W.; Badenes-Pérez, F.R.; Morrison, A.; Vogel, H.; Crickmore, N.; Kain, W.; Wang, P.; Heckel, D.G.; Jiggins, C.D. Parallel Evolution of Bacillus thuringiensis Toxin Resistance in Lepidoptera. Genetics 2011, 189, 675-679. [CrossRef]

30. Tiewsiri, K.; Wang, P. Differential alteration of two aminopeptidases $\mathrm{N}$ associated with resistance to Bacillus thuringiensis toxin Cry1Ac in cabbage looper. Proc. Natl. Acad. Sci. USA 2011, 108, 14037-14042. [CrossRef]

31. Xiao, Y.T.; Zhang, T.; Liu, C.X.; Heckel, D.G.; Li, X.C.; Tabashnik, B.E.; Wu, K.M. Mis-splicing of the ABCC2 gene linked with Bt toxin resistance in Helicoverpa armigera. Sci. Rep. 2014, 4, 6184. [CrossRef] 
32. Coates, B.S.; Siegfried, B.D. Linkage of an ABCC transporter to a single QTL that controls Ostrinia nubilalis larval resistance to the Bacillus thuringiensis Cry1Fa toxin. Insect Biochem. Mol. Biol. 2015, 63, 86-96. [CrossRef] [PubMed]

33. Smith, J.L.; Farhan, Y.; Schaafsma, A.W. Practical Resistance of Ostrinia nubilalis (Lepidoptera: Crambidae) to Cry1F Bacillus thuringiensis maize discovered in Nova Scotia, Canada. Sci. Rep. 2019, 9, 18247. [CrossRef]

34. Banerjee, R.; Hasler, J.; Meagher, R.; Nagoshi, R.; Hietala, L.; Huang, F.; Narva, K.; Jurat-Fuentes, J.L. Mechanism and DNA-based detection of field-evolved resistance to transgenic Bt corn in fall armyworm (Spodoptera frugiperda). Sci. Rep. 2017, 7, 10877. [CrossRef]

35. Flagel, L.; Lee, Y.W.; Wanjugi, H.; Swarup, S.; Brown, A.; Wang, J.L.; Kraft, E.; Greenplate, J.; Simmons, J.; Adams, N.; et al. Mutational disruption of the ABCC2 gene in fall armyworm, Spodoptera frugiperda, confers resistance to the Cry1Fa and Cry1A.105 insecticidal proteins. Sci. Rep. 2018, 8, 7255. [CrossRef] [PubMed]

36. Boaventura, D.; Ulrich, J.; Lueke, B.; Bolzan, A.; Okuma, D.; Gutbrod, O.; Geibel, S.; Zeng, Q.; Dourado, P.M.; Martinelli, S.; et al. Molecular characterization of CryiF resistance in fall armyworm, Spodoptera frugiperda from Brazil. Insect Biochem. Mol. Biol. 2020, 116, 103280. [CrossRef]

37. Boaventura, D.; Martin, M.; Pozzebon, A.; Mota-Sanchez, D.; Nauen, R. Monitoring of Target-Site Mutations Conferring Insecticide Resistance in Spodoptera frugiperda. Insects 2020, 11, 545. [CrossRef]

38. Guan, F.; Zhang, J.P.; Shen, H.W.; Wang, X.L.; Padovan, A.; Walsh, T.K.; Tay, W.T.; Gordon, K.H.J.; James, W.; Czepak, C.; et al. Whole-genome sequencing to detect mutations associated with resistance to insecticides and Bt proteins in Spodoptera frugiperda. Insect Sci. 2021, 28. [CrossRef]

39. Zhou, J.L.; Guo, Z.J.; Kang, S.; Qin, J.Y.; Gong, L.J.; Sun, D.; Guo, L.; Zhu, L.H.; Bai, Y.; Zhang, Z.Z.; et al. Reduced expression of the P-glycoprotein gene PxABCB1 is linked to resistance to Bacillus thuringiensis Cry1Ac toxin in Plutella xylostella (L.). Pest. Manag. Sci. 2020, 76, 712-720. [CrossRef]

40. Bretschneider, A.; Heckel, D.G.; Pauchet, Y. Three toxins, two receptors, one mechanism: Mode of action of Cry1A toxins from Bacillus thuringiensis in Heliothis virescens. Insect Biochem. Mol. Biol. 2016, 76, 109-117. [CrossRef]

41. Gómez, I.; Sánchez, J.; Miranda, R.; Bravo, A.; Soberón, M. Cadherin-like receptor binding facilitates proteolytic cleavage of helix alpha-1 in domain I and oligomer pre-pore formation of Bacillus thuringiensis Cry1Ab toxin. FEBS Lett. 2002, 513, 242-246. [CrossRef]

42. Ma, Y.M.; Zhang, J.F.; Xiao, Y.T.; Yang, Y.C.; Liu, C.X.; Peng, R.; Yang, Y.B.; Bravo, A.; Soberón, M.; Liu, K.Y. The Cadherin Cry1Ac Binding-Region is Necessary for the Cooperative Effect with ABCC2 Transporter Enhancing Insecticidal Activity of Bacillus thuringiensis Cry1Ac Toxin. Toxins 2019, 11, 538. [CrossRef]

43. Ren, X.L.; Jiang, W.L.; Ma, Y.J.; Hu, H.Y.; Ma, X.Y.; Ma, Y.; Li, G.Q. The Spodoptera exigua (Lepidoptera: Noctuidae) ABCC2 Mediates Cry1Ac Cytotoxicity and, in Conjunction with Cadherin, Contributes to Enhance Cry1Ca Toxicity in Sf9 Cells. J. Econ. Entomol. 2016, 109, 2281-2289. [CrossRef] [PubMed]

44. Martínez-Solís, M.; Pinos, D.; Endo, H.; Portugal, L.; Sato, R.; Ferré, J.; Herrero, S.; Hernández-Martínez, P. Role of Bacillus thuringiensis CrylA toxins domains in the binding to the ABCC2 receptor from Spodoptera exigua. Insect Biochem. Mol. Biol. 2018, 101, 47-56. [CrossRef]

45. Zhang, J.F.; Jin, M.H.; Yang, Y.C.; Liu, L.L.; Yang, Y.B.; Gomez, I.; Bravo, A.; Soberón, M.; Xiao, Y.T.; Liu, K.Y. The Cadherin Protein Is Not Involved in Susceptibility to Bacillus thuringiensis Cry1Ab or Cry1Fa Toxins in Spodoptera frugiperda. Toxins 2020, 12, 375. [CrossRef]

46. Jin, M.H.; Yang, Y.C.; Shan, Y.X.; Chakrabarty, S.; Cheng, Y.; Soberón, M.; Bravo, A.; Liu, K.Y.; Wu, K.M.; Xiao, Y.T. Two ABC transporters are differentially involved in the toxicity of two Bacillus thuringiensis Cry1 toxins to the invasive crop-pest Spodoptera frugiperda (J. E. Smith). Pest. Manag. Sci. 2021, 77, 1492-1501. [CrossRef]

47. Endo, H.; Tanaka, S.; Imamura, K.; Adegawa, S.; Kikuta, S.; Sato, R. Cry toxin specificities of insect ABCC transporters closely related to lepidopteran ABCC2 transporters. Peptides 2017, 98, 86-92. [CrossRef]

48. Stevens, T.; Song, S.S.; Bruning, J.B.; Choo, A.; Baxter, S.W. Expressing a moth ABCC2 gene in transgenic Drosophila causes susceptibility to Bt Cry1Ac without requiring a cadherin-like protein receptor. Insect Biochem. Mol. Biol. 2017, 80, 61-70. [CrossRef]

49. Tanaka, S.; Endo, H.; Adegawa, S.; Kikuta, S.; Sato, R. Functional characterization of Bacillus thuringiensis Cry toxin receptors explains resistance in insects. FEBS J. 2016, 283, 4474-4490. [CrossRef]

50. Wang, J.; Zhang, H.; Wang, H.D.; Zhao, S.; Zuo, Y.; Yang, Y.H.; Wu, Y.D. Functional validation of cadherin as a receptor of Bt toxin Cry1Ac in Helicoverpa armigera utilizing the CRISPR/Cas9 system. Insect Biochem. Mol. Biol. 2016, 76, 11-17. [CrossRef]

51. Yang, Y.H.; Yang, Y.J.; Gao, W.Y.; Guo, J.J.; Wu, Y.H.; Wu, Y.D. Introgression of a disrupted cadherin gene enables susceptible Helicoverpa armigera to obtain resistance to Bacillus thuringiensis toxin Cry1Ac. Bull. Entomol. Res. 2009, 99, 175-181. [CrossRef]

52. Huang, J.L.; Xu, Y.J.; Zuo, Y.Y.; Yang, Y.H.; Tabashnik, B.E.; Wu, Y.D. Evaluation of five candidate receptors for three Bt toxins in the beet armyworm using CRISPR-mediated gene knockouts. Insect Biochem. Mol. Biol. 2020, 121, 103361. [CrossRef]

53. Wang, S.H.; Kain, W.; Wang, P. Bacillus thuringiensis Cry1A toxins exert toxicity by multiple pathways in insects. Insect Biochem. Mol. Biol. 2018, 102, 59-66. [CrossRef]

54. Tanaka, S.; Miyamoto, K.; Noda, H.; Endo, H.; Kikuta, S.; Sato, R. Single amino acid insertions in extracellular loop 2 of Bombyx mori ABCC2 disrupt its receptor function for Bacillus thuringiensis Cry1Ab and Cry1Ac but not Cry1Aa toxins. Peptides 2016, 78, 99-108. [CrossRef] 
55. Adegawa, S.; Nakama, Y.; Endo, H.; Shinkawa, N.; Kikuta, S.; Sato, R. The domain II loops of Bacillus thuringiensis Cry1Aa form an overlapping interaction site for two Bombyx mori larvae functional receptors, ABC transporter $\mathrm{C} 2$ and cadherin-like receptor. Biochim. Biophys. Acta-Proteins Proteom. 2017, 1865, 220-231. [CrossRef]

56. Endo, H.; Tanaka, S.; Adegawa, S.; Ichino, F.; Tabunoki, H.; Kikuta, S.; Sato, R. Extracellular loop structures in silkworm ABCC transporters determine their specificities for Bacillus thuringiensis Cry toxins. J. Biol. Chem. 2018, 293, 8569-8577. [CrossRef]

57. Liu, L.L.; Chen, Z.W.; Yang, Y.C.; Xiao, Y.T.; Liu, C.X.; Ma, Y.M.; Soberón, M.; Bravo, A.; Yang, Y.B.; Liu, K.Y. A single amino acid polymorphism in ABCC2 loop 1 is responsible for differential toxicity of Bacillus thuringiensis Cry1Ac toxin in different Spodoptera (Noctuidae) species. Insect Biochem. Mol. Biol. 2018, 100, 59-65. [CrossRef]

58. Guo, Z.J.; Kang, S.; Chen, D.F.; Wu, Q.J.; Wang, S.L.; Xie, W.; Zhu, X.; Baxter, S.W.; Zhou, X.G.; Jurat-Fuentes, J.L.; et al. MAPK Signaling Pathway Alters Expression of Midgut ALP and ABCC Genes and Causes Resistance to Bacillus thuringiensis Cry1AC Toxin in Diamondback Moth. PLoS Genet. 2015, 11, 1005124. [CrossRef]

59. Li, J.H.; Ma, Y.M.; Yuan, W.L.; Xiao, Y.T.; Liu, C.X.; Wang, J.; Peng, J.X.; Peng, R.; Soberón, M.; Bravo, A.; et al. FOXA transcriptional factor modulates insect susceptibility to Bacillus thuringiensis Cry1Ac toxin by regulating the expression of toxin-receptor ABCC2 and ABCC3 genes. Insect Biochem. Mol. Biol. 2017, 88, 1-11. [CrossRef] [PubMed]

60. Wei, W.; Pan, S.; Ma, Y.M.; Xiao, Y.T.; Yang, Y.B.; He, S.J.; Bravo, A.; Soberón, M.; Liu, K.Y. GATAe transcription factor is involved in Bacillus thuringiensis Cry1Ac toxin receptor gene expression inducing toxin susceptibility. Insect Biochem. Mol. Biol. 2020, 118, 103306. [CrossRef]

61. Zhu, B.; Sun, X.; Nie, X.M.; Liang, P.; Gao, X.W. MicroRNA-998-3p contributes to Cry1Ac-resistance by targeting ABCC2 in lepidopteran insects. Insect Biochem. Mol. Biol. 2020, 117, 103283. [CrossRef]

62. Knowles, B.H.; Ellar, D.J. Colloid-osmotic lysis is a general feature of the mechanism of action of Bacillus thuringiensis deltaendotoxins with different insect specificity. Biochim. Biophys. Acta 1987, 924, 509-518. [CrossRef]

63. Chen, Z.W.; He, F.; Xiao, Y.T.; Liu, C.X.; Li, J.H.; Yang, Y.B.; Ai, H.; Peng, J.X.; Hong, H.Z.; Liu, K.Y. Endogenous expression of a Bt toxin receptor in the Cry1Ac-susceptible insect cell line and its synergistic effect with cadherin on cytotoxicity of activated Cry1Ac. Insect Biochem. Mol. Biol. 2015, 59, 1-17. [CrossRef] [PubMed]

64. Wei, J.Z.; Liang, G.M.; Wu, K.M.; Gu, S.H.; Guo, Y.Y.; Ni, X.Z.; Li, X.C. Cytotoxicity and binding profiles of activated Cry1Ac and $\mathrm{Cry} 2 \mathrm{Ab}$ to three insect cell lines. Insect Sci. 2018, 25, 655-666. [CrossRef]

65. Soberón, M.; Portugal, L.; Garcia-Gómez, B.I.; Sánchez, J.; Onofre, J.; Gómez, I.; Pacheco, S.; Bravo, A. Cell lines as models for the study of Cry toxins from Bacillus thuringiensis. Insect Biochem. Mol. Biol. 2018, 93, 66-78. [CrossRef]

66. Stodola, T.J.; Andow, D.A. F-2 screen variations and associated statistics. J. Econ. Entomol. 2004, 97, 1756-1764. [CrossRef]

67. Tay, W.T.; Mahon, R.J.; Heckel, D.G.; Walsh, T.K.; Downes, S.; James, W.J.; Lee, S.F.; Reineke, A.; Williams, A.K.; Gordon, K.H.J. Insect Resistance to Bacillus thuringiensis Toxin Cry2Ab Is Conferred by Mutations in an ABC Transporter Subfamily A Protein. PLoS Genet. 2015, 11, e1005534. [CrossRef]

68. Song, X.; Kain, W.; Cassidy, D.; Wang, P. Resistance to Bacillus thuringiensis Toxin Cry2Ab in Trichoplusia ni Is Conferred by a Novel Genetic Mechanism. Appl. Environ. Microbiol. 2015, 81, 5184-5195. [CrossRef]

69. Yang, X.W.; Chen, W.B.; Song, X.Z.; Ma, X.L.; Cotto-Rivera, R.O.; Kain, W.; Chu, H.N.; Chen, Y.R.; Fei, Z.J.; Wang, P. Mutation of ABC transporter ABCA2 confers resistance to Bt toxin Cry2Ab in Trichoplusia ni. Insect Biochem. Mol. Biol. 2019, 112, 103209. [CrossRef]

70. Mathew, L.G.; Ponnuraj, J.; Mallappa, B.; Chowdary, L.R.; Zhang, J.W.; Tay, W.T.; Walsh, T.K.; Gordon, K.H.J.; Heckel, D.G.; Downes, S.; et al. ABC transporter mis-splicing associated with resistance to Bt toxin Cry2Ab in laboratory-and field-selected pink bollworm. Sci. Rep. 2018, 8, 13531. [CrossRef] [PubMed]

71. Fabrick, J.A.; LeRoy, D.M.; Unnithan, G.C.; Yelich, A.J.; Carrière, Y.; Li, X.C.; Tabashnik, B.E. Shared and Independent Genetic Basis of Resistance to Bt Toxin Cry2Ab in Two Strains of Pink Bollworm. Sci. Rep. 2020, 10, 7988. [CrossRef]

72. Chen, L.; Wei, J.Z.; Liu, C.; Zhang, W.N.; Wang, B.J.; Niu, L.L.; Liang, G.M. Specific Binding Protein ABCC1 Is Associated With Cry2Ab Toxicity in Helicoverpa armigera. Front. Physiol. 2018, 9, 745. [CrossRef]

73. Khan, S.A.; Reichelt, M.; Heckel, D.G. Functional analysis of the ABCs of eye color in Helicoverpa armigera with CRISPR/Cas9induced mutations. Sci. Rep. 2017, 7, 40025. [CrossRef]

74. Reding, K.; Pick, L. High-Efficiency CRISPR/Cas9 Mutagenesis of the white Gene in the Milkweed Bug Oncopeltus fasciatus. Genetics 2020, 215, 1027-1037. [CrossRef]

75. Wang, J.; Wang, H.D.; Liu, S.Y.; Liu, L.P.; Tay, W.T.; Walsh, T.K.; Yang, Y.H.; Wu, Y.D. CRISPR/Cas9 mediated genome editing of Helicoverpa armigera with mutations of an $\mathrm{ABC}$ transporter gene HaABCA2 confers resistance to Bacillus thuringiensis Cry2A toxins. Insect Biochem. Mol. Biol. 2017, 87, 147-153. [CrossRef]

76. Li, X.Y.; Miyamoto, K.; Takasu, Y.; Wada, S.; Iizuka, T.; Adegawa, S.; Sato, R.; Watanabe, K. ATP-Binding Cassette Subfamily a Member 2 Is a Functional Receptor for Bacillus thuringiensis Cry2A Toxins in Bombyx mori, But Not for Cry1A, Cry1C, Cry1D, Cry1F, or Cry9A Toxins. Toxins 2020, 12, 104. [CrossRef]

77. Guo, Z.J.; Sun, D.; Kang, S.; Zhou, J.L.; Gong, L.J.; Qin, J.Y.; Guo, L.; Zhu, L.H.; Bai, Y.; Luo, L.; et al. CRISPR/Cas9-mediated knockout of both the PxABCC2 and PxABCC3 genes confers high-level resistance to Bacillus thuringiensis Cry1Ac toxin in the diamondback moth, Plutella xylostella (L.). Insect Biochem. Mol. Biol. 2019, 107, 31-38. [CrossRef] 
78. Liu, Z.X.; Fu, S.; Ma, X.L.; Baxter, S.W.; Vasseur, L.; Xiong, L.; Huang, Y.P.; Yang, G.; You, S.J.; You, M.S. Resistance to Bacillus thuringiensis Cry1Ac toxin requires mutations in two Plutella xylostella ATP-binding cassette transporter paralogs. PLoS Pathog. 2020, 16, e1008697. [CrossRef]

79. Wang, J.; Ma, H.H.; Zhao, S.; Huang, J.L.; Yang, Y.H.; Tabashnik, B.E.; Wu, Y.D. Functional redundancy of two ABC transporter proteins in mediating toxicity of Bacillus thuringiensis to cotton bollworm. PLoS Pathog. 2020, 16, e1008427. [CrossRef]

80. Wang, X.L.; Xu, Y.J.; Huang, J.L.; Jin, W.Z.; Yang, Y.H.; Wu, Y.D. CRISPR-Mediated Knockout of the ABCC2 Gene in Ostrinia furnacalis Confers High-Level Resistance to the Bacillus thuringiensis Cry1Fa Toxin. Toxins 2020, 12, 246. [CrossRef]

81. Jin, L.; Wang, J.; Guan, F.; Zhang, J.P.; Yu, S.; Liu, S.Y.; Xue, Y.Y.; Li, L.L.; Wu, S.W.; Wang, X.L.; et al. Dominant point mutation in a tetraspanin gene associated with field-evolved resistance of cotton bollworm to transgenic Bt cotton. Proc. Natl. Acad. Sci. USA 2018, 115, 11760-11765. [CrossRef]

82. Xiao, Y.T.; Liu, K.Y.; Zhang, D.D.; Gong, L.L.; He, F.; Soberón, M.; Bravo, A.; Tabashnik, B.E.; Wu, K.M. Resistance to Bacillus thuringiensis Mediated by an ABC Transporter Mutation Increases Susceptibility to Toxins from Other Bacteria in an Invasive Insect. PLoS Pathog. 2016, 12, e1005450. [CrossRef] [PubMed]

83. Abdelgaffar, H.; Perera, O.P.; Jurat-Fuentes, J.L. ABC transporter mutations in Cry1F-resistant fall armyworm (Spodoptera frugiperda) do not result in altered susceptibility to selected small molecule pesticides. Pest. Manag. Sci. 2021, 77, 949-955. [CrossRef]

84. Zuo, Y.Y.; Huang, J.L.; Wang, J.; Feng, Y.; Han, T.T.; Wu, Y.D.; Yang, Y.H. Knockout of a P-glycoprotein gene increases susceptibility to abamectin and emamectin benzoate in Spodoptera exigua. Insect Mol. Biol. 2018, 27, 36-45. [CrossRef]

85. Xu, J.; Wang, Z.Y.; Wang, Y.F.; Ma, H.H.; Zhu, H.; Liu, J.; Zhou, Y.; Deng, X.L.; Zhou, X.M. ABCC2 participates in the resistance of Plutella xylostella to chemical insecticides. Pestic. Biochem. Physiol. 2020, 162, 52-59. [CrossRef]

86. Pauchet, Y.; Bretschneider, A.; Augustin, S.; Heckel, D.G. A P-Glycoprotein Is Linked to Resistance to the Bacillus thuringiensis Cry3Aa Toxin in a Leaf Beetle. Toxins 2016, 8, 362. [CrossRef]

87. Niu, X.P.; Kassa, A.; Hasler, J.; Griffin, S.; Perez-Ortega, C.; Procyk, L.; Zhang, J.; Kapka-Kitzman, D.M.; Nelson, M.E.; Lu, A. Functional validation of DvABCB1 as a receptor of Cry3 toxins in western corn rootworm, Diabrotica virgifera virgifera. Sci. Rep. 2020, 10, 15830. [CrossRef]

88. Jakka, S.R.K.; Shrestha, R.B.; Gassmann, A.J. Broad-spectrum resistance to Bacillus thuringiensis toxins by western corn rootworm (Diabrotica virgifera virgifera). Sci. Rep. 2016, 6, 27860. [CrossRef] [PubMed]

89. Guo, Z.J.; Kang, S.; Zhu, X.; Xia, J.X.; Wu, Q.J.; Wang, S.L.; Xie, W.; Zhang, Y.J. Down-regulation of a novel ABC transporter gene (Pxwhite) is associated with Cry1Ac resistance in the diamondback moth, Plutella xylostella (L.). Insect Biochem. Mol. Biol. 2015, 59, 30-40. [CrossRef] [PubMed]

90. Guo, Z.J.; Kang, S.; Zhu, X.; Xia, J.X.; Wu, Q.J.; Wang, S.L.; Xie, W.; Zhang, Y.J. The novel ABC transporter ABCH1 is a potential target for RNAi-based insect pest control and resistance management. Sci. Rep. 2015, 5, 13728. [CrossRef]

91. Zhang, T.T.; Coates, B.S.; Wang, Y.Q.; Wang, Y.D.; Bai, S.X.; Wang, Z.Y.; He, K.L. Down-regulation of aminopeptidase N and $\mathrm{ABC}$ transporter subfamily $\mathrm{G}$ transcripts in Cry1Ab and Cry1Ac resistant Asian corn borer, Ostrinia furnacalis (Lepidoptera: Crambidae). Int. J. Biol. Sci. 2017, 13, 835-851. [CrossRef] [PubMed]

92. Ocelotl, J.; Sánchez, J.; Gómez, I.; Tabashnik, B.E.; Bravo, A.; Soberón, M. ABCC2 is associated with Bacillus thuringiensis Cry1Ac toxin oligomerization and membrane insertion in diamondback moth. Sci. Rep. 2017, 7, 2386. [CrossRef]

93. Pinos, D.; Martínez-Solís, M.; Herrero, S.; Ferré, J.; Hernández-Martínez, P. The Spodoptera exigua ABCC2 Acts as a Cry1A Receptor Independently of its Nucleotide Binding Domain II. Toxins 2019, 11, 172. [CrossRef]

94. Tanaka, S.; Endo, H.; Adegawa, S.; Iizuka, A.; Imamura, K.; Kikuta, S.; Sato, R. Bombyx mori ABC transporter C2 structures responsible for the receptor function of Bacillus thuringiensis CrylAa toxin. Insect Biochem. Mol. Biol. 2017, 91, 44-54. [CrossRef]

95. Núñez-Ramírez, R.; Huesa, J.; Bel, Y.; Ferré, J.; Casino, P.; Arias-Palomo, E. Molecular architecture and activation of the insecticidal protein Vip3Aa from Bacillus thuringiensis. Nat. Commun. 2020, 11, 3974. [CrossRef]

96. Bayly-Jones, C.; Bubeck, D.; Dunstone, M.A. The mystery behind membrane insertion: A review of the complement membrane attack complex. Philos. Trans. R. Soc. B-Biol. Sci. 2017, 372, 20160221. [CrossRef] [PubMed]

97. Gatsogiannis, C.; Merino, F.; Roderer, D.; Balchin, D.; Schubert, E.; Kuhlee, A.; Hayer-Hartl, M.; Raunser, S. Tc toxin activation requires unfolding and refolding of a beta-propeller. Nature 2018, 563, 209-213. [CrossRef] [PubMed]

98. Grochulski, P.; Masson, L.; Borisova, S.; Pusztai-Carey, M.; Schwartz, J.L.; Brousseau, R.; Cygler, M. Bacillus thuringiensis CryIA(a) insecticidal toxin-Crystal structure and channel formation. J. Mol. Biol. 1995, 254, 447-464. [CrossRef] [PubMed]

99. Li, J.D.; Carroll, J.; Ellar, D.J. Crystal structure of insecticidal delta-endotoxin from Bacillus thuringiensis at 2.5 A resolution. Nature 1991, 353, 815-821. [CrossRef] [PubMed]

100. Evdokimov, A.G.; Moshiri, F.; Sturman, E.J.; Rydel, T.J.; Zheng, M.Y.; Seale, J.W.; Franklin, S. Structure of the full-length insecticidal protein Cry1Ac reveals intriguing details of toxin packaging into in vivo formed crystals. Protein Sci. 2014, 23, 1491-1497. [CrossRef] [PubMed] 